\title{
Blood Management in Revision Total Hip Arthroplasty for Metal-on-Metal Devices: The Efficiency of an Intraoperative Cell Salvage System
}

\author{
Werner Maurer-Ertl ${ }^{1} \cdot$ Andreas Fellner $^{2} \cdot$ Patrick Reinbacher $^{1} \cdot$ Michael Maier $^{1} \cdot$ Andreas Leithner $^{1}$. \\ Joerg Friesenbichler ${ }^{1}$
}

Received: 25 May 2019 / Accepted: 9 July 2019 / Published online: 24 January 2020

(C) The Author(s) 2020

\begin{abstract}
Background The aim of this series was to investigate the efficiency of an intraoperative cell salvage system (ICS) removing metal ions during revision of metal-on-metal (MoM) devices to proof the possibility of re-transfusion of the collected blood. Materials and methods Between 2014 and 2018, five consecutive patients underwent revision surgery of their MoM total hip arthroplasty due to wear of the polyethylene-metal sandwich inlay or local massive metallosis with aseptic loosing of the cup. Aspiration of joint fluid of all hip prostheses was done and blood was taken to measure the metal ion concentrations, preoperatively. Perioperatively, blood was collected using an ICS before and after filtration and analyzed for Co and $\mathrm{Cr}$ concentrations. At that time, there was no re-transfusion of the collected and filtrated blood due to unknown metal ion concentrations.

Results The mean preoperative serum Co and Cr concentrations in the blood were $31.28 \mu \mathrm{g} / \mathrm{L}$ (range 0.22-77.47) and $17.33 \mu \mathrm{g} / \mathrm{L}$ (range 0.59-51.31), whereas the mean local concentrations in the aspiration fluid were 728-fold and 822-fold higher. The Co and $\mathrm{Cr}$ concentrations measured in the collected blood before filtration were $70.61 \mu \mathrm{g} / \mathrm{L}$ (range 9.40-173.00) and $337.21 \mu \mathrm{g} / \mathrm{L}$ (range 8.76-1383.0) and decreased markedly to average concentrations of $15.49 \mu \mathrm{g} / \mathrm{L}$ and $41.88 \mu \mathrm{g} / \mathrm{L}$, respectively. These differences were statistically not significant (Co: $p=0.117, \mathrm{Cr}: p=0.175)$, although the mean reduction rates were $78 \%$ and $88 \%$ for Co and Cr, respectively.

Conclusion The current series showed that in case of revision of MoM hip devices, metal ions are still contained in the collected blood following filtration using a modern high-level ICS. Therefore, we would only recommend blood re-transfusion in case of low preoperative $\mathrm{Co}$ and $\mathrm{Cr}$ concentrations and sufficient renal function to warrant patients' safety.
\end{abstract}

Keywords Arthroplasty $\cdot$ Hip $\cdot$ Cobalt $\cdot$ Chromium $\cdot$ Blood salvage

\section{Introduction}

Data of several national and international registries are showing increasing numbers of total hip and knee arthroplasties (THA \& TKA) all over the world. On the other hand, the number of revisions for failed arthroplasties is also increasing. The fourth generation of metal-on-metal (MoM)

Joerg Friesenbichler

joerg.friesenbichler@medunigraz.at

1 Department of Orthopaedics and Trauma, Medical University of Graz, Auenbruggerplatz 5, 8036 Graz, Austria

2 Department of Anaesthesiology, Medical University of Graz, Auenbruggerplatz 5, 8036 Graz, Austria
THA was introduced at the beginning of the twenty-first century and was popular for joint replacement due to propagated favorable wear patterns and high range of motion, especially in young and physically active patients. Nevertheless, the number of revisions for failed MoM hip arthroplasties has increased within the last 10 years due to increased metal ion concentrations ( $\mathrm{Co} \& \mathrm{Cr}$ ) and adverse reactions to metal debris (ARMD), although the long-term effects of systemic exposure still remain unclear [1,2]. The international accepted threshold of $7.0 \mu \mathrm{g} / \mathrm{L}$ for revision surgery of MoM devices was recommended by the UK Medicines and Healthcare products Regulatory Agency (MHRA) and several orthopedic societies [1,3].

In the literature, it has been shown that marked blood loss during primary or revision joint arthroplasty may lead 
to higher rates of transfusion, which may negatively affect surgical outcomes due to possible related complications [4]. Therefore, intraoperative cell salvage (ICS) has been shown to be a valuable and effective method to reduce the requirement of allogenic blood transfusion and costs following THA or TKA [5, 6].

The aim of the current series was to investigate the efficiency of an ICS system removing metal ions during revision of failed MoM devices to perform a re-transfusion of the collected blood. Furthermore, measurements of $\mathrm{Co}$ and $\mathrm{Cr}$ concentrations were done to investigate if there was a correlation between blood levels, the levels measured in the aspiration fluid, and the levels measured in the ICS system.

\section{Materials and Methods}

Between 2014 and 2018, five consecutive patients underwent revision surgery of their MoM total hip arthroplasty due to wear of the polyethylene-metal sandwich inlay or local massive metallosis with aseptic loosing of the cup following an average follow-up of 172 months (range 85-216) after index procedure. There were four female patients and one male patient. The mean age at time of index surgery was 45 years (range 20-71) and 59 years at time of revision (range 37-88). Patient's demographics are shown in Table 1.

All hip prostheses underwent percutaneous aspiration to exclude periprosthetic infection as well as to determine local metal ion concentrations; further blood was taken to measure the metal ion levels in the whole blood, 4-6 weeks preoperatively. Perioperatively, blood was collected using an autotransfusion system called OrthoPAT (Haemonetics Corp., Braintree, Mass.) with an integrated percolation system. The SmartSuction Harmony system of the OrthoPAT reduces haemolysis of red blood cells. The wound blood was collected in a filtered reservoir; afterwards, red blood cells were separated by centrifugation and washed with saline solution. The concentrated red blood cells were collected in a transfusion bag. For metal ion determination, blood was obtained from the reservoir bag before and after centrifugation and wash out.

Table 1 Patients' demographics
At that time, there was no re-transfusion of the collected and filtrated blood due to unknown metal ion concentrations.

An external laboratory (Medizinische und chemische Labordiagnostik Lorenz \& Petek GmbH, Graz, Austria) was hired to determined $\mathrm{Co}$ and $\mathrm{Cr}$ concentrations. Analysis was done using electrothermal graphite furnace atomic absorption spectrometry (ET ASS). The levels of metal ions were recorded in concentrations expressed as $\mu \mathrm{g} / \mathrm{L}$. Detection limits were $0-0.5 \mu \mathrm{g} / \mathrm{L}$ for $\mathrm{Co}$ and $0-1.9 \mu \mathrm{g} / \mathrm{L}$ for $\mathrm{Cr}$.

Statistical analysis was done using the PASW Statistics 22.0 program (SPSS Inc., Chicago, IL). Due to the asymmetric distribution of data, a nonparametric test (Mann-Whitney $U$ test) was used. A $p$ value of $<0.05$ was considered to be statistically significant.

\section{Results}

The mean preoperative whole blood $\mathrm{Co}$ and $\mathrm{Cr}$ concentrations were $31.28 \mu \mathrm{g} / \mathrm{L}$ (range $0.22-77.40$ ) and $17.33 \mu \mathrm{g} / \mathrm{L}$ (range 0.59-51.31), whereas the local concentrations in the aspiration fluid were 728 -fold and 822-fold higher [mean: Co: $22,789.43 \mu \mathrm{g} / \mathrm{L}$ (range $35.10-73,390.00$ ) and $\mathrm{Cr}$ : $14,254.71 \mu \mathrm{g} / \mathrm{L}$ (range 4.93-57,500.00), Tables 2 and 3].

The $\mathrm{Co}$ and $\mathrm{Cr}$ concentrations measured in the collected blood from the reservoir bag before centrifugation and wash

Table 2 Results of metal ion determination for Cobalt (Co) for each patient in the blood, the aspiration fluid, and in the used intraoperative cell salvage system

\begin{tabular}{lcllc}
\hline No & $\begin{array}{l}\text { Whole blood } \\
\text { preopera- } \\
\text { tively }\end{array}$ & $\begin{array}{l}\text { Aspiration } \\
\text { fluid }\end{array}$ & $\begin{array}{l}\text { OrthoPAT } \\
\text { before filtra- } \\
\text { tion }\end{array}$ & $\begin{array}{l}\text { OrthoPAT } \\
\text { after filtra- } \\
\text { tion }\end{array}$ \\
\hline 1 & 0.40 & 35.10 & 9.40 & 0.30 \\
2 & 71.70 & 73,390 & 118 & 17.00 \\
3 & 6.70 & 112.70 & 43 & 2.60 \\
4 & 77.40 & 40,360 & 173 & 57.50 \\
5 & 0.22 & 49.34 & 9.63 & 0.07 \\
All (mean) & 31.28 & $22,789.43$ & 70.61 & 15.49 \\
\hline
\end{tabular}

Furthermore, the average results of Co determination for all patients together are used for statistical analysis. All results are shown as $\mu \mathrm{g} / \mathrm{L}$

\section{Table 1 Patients' demographics}

\begin{tabular}{llllllc}
\hline No & Sex & $\begin{array}{l}\text { Year of implanta- } \\
\text { tion MoM device }\end{array}$ & Type of MoM bearing & $\begin{array}{l}\text { Age at index } \\
\text { operation } \\
\text { (years) }\end{array}$ & $\begin{array}{l}\text { Age at Revi- } \\
\text { sion (years) }\end{array}$ & $\begin{array}{l}\text { Time till revi- } \\
\text { sion (months) }\end{array}$ \\
\hline 1 & F & 2003 & Metasul & 50 & 61 & 143 \\
2 & F & 1998 & Metasul & 20 & 37 & 212 \\
3 & M & 1998 & Metasul & 71 & 88 & 205 \\
4 & F & 2009 & ASR XL Head & 52 & 59 & 85 \\
5 & F & 2000 & Metasul & 35 & 53 & 216 \\
\hline
\end{tabular}


Table 3 Results of chromium (Cr) level determination for each patient in the blood, the aspiration fluid, and in the used intraoperative cell salvage system

\begin{tabular}{lcllr}
\hline No & $\begin{array}{l}\text { Whole blood } \\
\text { preopera- } \\
\text { tively }\end{array}$ & $\begin{array}{l}\text { Aspiration } \\
\text { fluid }\end{array}$ & $\begin{array}{l}\text { OrthoPAT } \\
\text { before filtra- } \\
\text { tion }\end{array}$ & $\begin{array}{l}\text { OrthoPAT } \\
\text { after filtra- } \\
\text { tion }\end{array}$ \\
\hline 1 & 0.59 & 63.10 & 14.07 & 1.13 \\
2 & 51.31 & 13,560 & 1383 & 136.40 \\
3 & 1.43 & 4.93 & 8.76 & 0.75 \\
4 & 31.68 & 57,500 & 216.50 & 68.70 \\
5 & 1.66 & 145.50 & 63.70 & 2.43 \\
All (mean) & 17.33 & $14,254.71$ & 337.21 & 41.88 \\
\hline
\end{tabular}

Further, average results of $\mathrm{Cr}$ determination for all patients together are used for statistical analysis. All results are shown as $\mu \mathrm{g} / \mathrm{L}$

out were $70.61 \mu \mathrm{g} / \mathrm{L}$ (range 9.40-173.00) and $337.21 \mu \mathrm{g} / \mathrm{L}$ (range 8.76-1383.00), respectively. Following centrifugation and wash out, the metal ion levels decreased markedly to an average of $15.49 \mu \mathrm{g} / \mathrm{L}$ (range $0.07-57.50$ ) and $41.88 \mu \mathrm{g} / \mathrm{L}$ (0.75-136.40) for Co and Cr, respectively (Tables 2 and 3). Nevertheless, these differences were statistically not significant (Co: $p=0.117, \mathrm{Cr}: p=0.175)$, although the mean reduction rates were $78 \%$ and $88 \%$ for $\mathrm{Co}$ and $\mathrm{Cr}$, respectively. Statistical analysis did not show any significant correlation between measured $\mathrm{Co}$ and $\mathrm{Cr}$ levels and localisation of determination.

\section{Discussion}

Several studies showed that intraoperative cell salvage reduces allogenic blood transfusion rates in joint arthroplasty and emphasized the cost-effectiveness. These observations are also relevant for revision arthroplasties. The current series showed that in case of revision of MoM bearings, especially older-generations like the Metasul bearing, but also the fourth generation MoM implants, an autologous blood re-transfusion should only be done in selected cases with low local concentrations in the aspiration fluid as well as low preoperative whole blood $\mathrm{Co}$ and $\mathrm{Cr}$ concentrations to warrant patients' safety. The recent study clearly showed that metal ions are still contained in the collected blood following centrifugation and wash out, despite using a modern high-level percolated autotransfusion system. Nevertheless, a significant correlation between measured serum metal ion concentrations and metal ion concentrations determined in the aspiration fluid or the blood of the ICS could not be shown. One reason could be the small number of patients enrolled and sometimes differences in measured levels between the various locations might be due to some kind of systemical and local diluting effect.
There are several risk factors for elevated $\mathrm{Co}$ and $\mathrm{Cr}$ levels following MoM and MoC (metal-on-ceramic) THA reported in the literature. Implant position (inclination), bigger femoral head size, higher range of motion, higher grade of activity, and female sex are known to be at risk for increased metal ion concentrations [2, 7]. Another wellknown source of metal ions is the taper junction between the femoral stem and the femoral head [2, 7]. All these factors might also be the cause for the different metal ion levels in the current series.

Sizer et al. [8]. identified preoperative anemia, older age, multiple comorbidities, increased operative time, and postoperative anticoagulation as risk factors for higher blood loss and transfusion rates.

Holt et al. [9]. showed that a multimodal, multidisciplinary approach to perioperative blood management, including preoperative hemoglobin optimization, minimization of perioperative blood loss, and adherence to evidence-based transfusion guidelines, resulted in a significant reduction of transfusion rates in THA and TKA.

Preoperative blood donation and intra- and postoperative blood collection as well as administration of pharmaceutical agents to reduce blood loss (e.g., tranexamic acid) or to stimulate the production of erythrocytes (e.g., erythropoietin) have been proposed as alternative techniques to transfusion of homologous blood $[6,10]$.

Like in the current series, Ganapathi et al. [11] showed that the processing of recovered blood during revision of MoM devices in a commercial cell saver significantly reduced the total metal load. Furthermore, it was demonstrated that the re-infusion of collected blood did not result in elevated metal ion levels in the immediate postoperative period [11]. In contrast to that, the collected blood in the current study was not re-infused due to the risk of potential side effects or the fear of additional metal ion increment. Furthermore, renal function must always be taken into consideration due to the fact that limited renal function may additionally contribute to an accumulation of metal ions.

In an earlier series, Parker et al. [12] related that leukocyte reduction filters of ICS systems might be effective in reducing metal ion concentrations in recovered blood used for autologous re-infusion, but further investigations were recommended to prove this fact. On the other hand, several authors reported severe cases of neuropathies and intoxications induced by highly increased $\mathrm{Co}$ and $\mathrm{Cr}$ levels due to excessive wear following metal-on-polyethylene and ceramic-on-metal THA [13-20].

There are several limitations of the current series: (1) there are only five consecutive patients included, but we think that this is enough to show that the usage of a standard ICS is not sufficient for the complete removal of all Co and $\mathrm{Cr}$ ions from the salvaged blood; (2) there were no further postoperative metal ion determinations to illustrate the trend 
of the $\mathrm{Co}$ and $\mathrm{Cr}$ levels, but, as shown in the literature, we expect a further decline in concentration.

Finally, in cases of revision of MoM devices, we would only recommend the re-transfusion of collected autologous blood in case of low preoperative $\mathrm{Co}$ and $\mathrm{Cr}$ concentrations and sufficient renal function to warrant patients' safety. At least, the decision depends on the surgeons' preference, but the patient has to be informed about possible risks and benefits.

Acknowledgement Open access funding provided by Medical University of Graz.

\section{Compliance with Ethical Standards}

Conflict of interest All authors approved the manuscript and all authors declare that are no conflicts of interest regarding the publication.

Ethical standard statement The current study was approved by the local ethic committee.

Informed consent The authors certify that they have obtained all appropriate patient consent forms. In the form, the patient(s) has/have given his/her/their consent for his/her/their images and other clinical information to be reported in the journal. The patients understand that their names and initials will not be published and due efforts will be made to conceal their identity, but anonymity cannot be guaranteed.

Open Access This article is licensed under a Creative Commons Attribution 4.0 International License, which permits use, sharing, adaptation, distribution and reproduction in any medium or format, as long as you give appropriate credit to the original author(s) and the source, provide a link to the Creative Commons licence, and indicate if changes were made. The images or other third party material in this article are included in the article's Creative Commons licence, unless indicated otherwise in a credit line to the material. If material is not included in the article's Creative Commons licence and your intended use is not permitted by statutory regulation or exceeds the permitted use, you will need to obtain permission directly from the copyright holder. To view a copy of this licence, visit http://creativecommons.org/licenses/by/4.0/.

\section{References}

1. Maurer-Ertl, W., Friesenbichler, J., Holzer, L. A., et al. (2017). Recall of the ASR XL head and hip resurfacing systems. Orthopedics., 40, e340-e347.

2. Maurer-Ertl, W., Pranckh-Matzke, D., Friesenbichler, J., et al. (2017). Clinical results and serum metal ion concentrations following ceramic-on-metal total hip arthroplasty at a mean followup of 60 months. BioMed Research International, 2017, 3726029.

3. Medicines and Healthcare products Regulatory Agency: Alerts and recalls for drugs and medical devices: Metal-on-metal (MoM) hip replacements - updated advice with patient follow ups MDA/2012/036

4. Reijngoud, L. W., Pattyn, C., De Haan, R., et al. (2009). Does intraoperative cell salvage remove cobalt and chromium from reinfused blood? Journal of Arthroplasty, 24, 1125-1129.

5. Bridgens, J. P., Evans, C. R., Dobson, P. M., \& Hamer, A. J. (2007). Intraoperative red blood-cell salvage in revision hip surgery. A case-matched study. Journal of Bone and Joint Surger, $89,270-275$.

6. Crescibene, A., Martire, F., Gigliotti, P., Rende, A., \& Candela, M. (2015). Postoperative autologous reinfusion in total knee replacement. Journal of Blood Transfusion, 2015, 826790.

7. Lainiala, O. S., Moilanen, T. P. S., Hart, A. J., Huhtala, H. S. A., Sabah, S. A., \& Eskelinen, A. P. (2016). Higher blood cobalt and chromium levels in patients with unilateral metal-on-metal total hip arthroplasties compared to hip resurfacings. Journal of Arthroplasty, 31, 1261-1266.

8. Sizer, S. C., Cherian, J. J., Elmallah, R. D., Pierce, T. P., Beaver, W. B., \& Mont, M. A. (2015). Predicting blood loss in total knee and hip arthroplasty. Orthopedic Clinics of North America, 46, 445-459.

9. Holt, J. B., Miller, B. J., Callaghan, J. J., Clark, C. R., Willenborg, M. D., \& Noiseux, N. O. (2016). Minimizing blood transfusion in total hip and knee arthroplasty through a multimodal approach. Journal of Arthroplasty, 31, 378-382.

10. Baker, J. E., Pavenski, K., Pirani, R. A., et al. (2015). Universal tranexamic acid therapy to minimize transfusion for major joint arthroplasty: a retrospective analysis of protocol implementation. Canadian Journal of Anaesthesia, 62, 1179-1187.

11. Ganapathi M, Jones S, Roberts P. P47 metal levels in 'cell saver' blood recovered during revision hip arthroplasty. Bone and Joint Journal

12. Parker, L. M., Yazer, M. H., \& Waters, J. H. (2017). Metallosis identified via intraoperative cell salvage: a case report. A A Case Report, 8, 67-69.

13. Pazzaglia, U. E., Apostoli, P., Congiu, T., Catalani, S., Marchese, M., \& Zarattini, G. (2011). Cobalt, chromium and molybdenum ions kinetics in the human body: data gained from a total hip replacement with massive third body wear of the head and neuropathy by cobalt intoxication. Arch Orthop Trauma Surg., 131(9), 1299-308. https://doi.org/10.1007/s00402-011-1268-7.

14. Apostoli, P., Catalani, S., Zaghini, A., et al. (2013). High doses of cobalt induce optic and auditory neuropathy. Experimental and Toxicologic Pathology, 65, 719-727.

15. Rizzetti, M. C., Catalani, S., Apostoli, P., \& Padovani, A. (2011). Cobalt toxicity after total hip replacement: a neglected adverse effect? Muscle Nerve, 43, 146-147. (author reply 147).

16. Zywiel, M. G., Brandt, J. M., Overgaard, C. B., Cheung, A. C., Turgeon, T. R., \& Syed, K. A. (2013). Fatal cardiomyopathy after revision total hip replacement for fracture of a ceramic liner. The Bone \& Joint journal., 95-B, 31-37.

17. Steens, W., Loehr, J. F., \& von Foerster, G. (2006). Katzer A [Chronic cobalt poisoning in endoprosthetic replacement]. Orthopade, 35, 860-864.

18. Ikeda, T., Takahashi, K., Kabata, T., Sakagoshi, D., Tomita, K., \& Yamada, M. (2010). Polyneuropathy caused by cobalt-chromium metallosis after total hip replacement. Muscle and Nerve, 42, $140-143$.

19. Oldenburg, M., Wegner, R., \& Baur, X. (2009). Severe cobalt intoxication due to prosthesis wear in repeated total hip arthroplasty. Journal of Arthroplasty, 24(825), e815-e820.

20. Pelclova, D., Sklensky, M., Janicek, P., \& Lach, K. (2012). Severe cobalt intoxication following hip replacement revision: clinical features and outcome. Clinical Toxicology (Philadelphia, PA), 50, $262-265$.

Publisher's Note Springer Nature remains neutral with regard to jurisdictional claims in published maps and institutional affiliations. 